\title{
Chromosomal Abnormalities in 238 Couples with Recurrent Miscarriages in Morocco
}

\author{
Hanane Houmaid ${ }^{1 *}$, Chadli El Bekkay², Sanaa Nassereddine ${ }^{2}$, Hayat Talbi ${ }^{3}$, \\ Loubna Amehdare4, Abderraouf Hilali3,4 \\ ${ }^{1}$ Department of Gyneacology and Obstetrics, Mohammed VI Hospital, Chichaoua, Morocco \\ ${ }^{2}$ Department of Cytogenetics, Institut Pasteur, Casablanca, Morocco \\ ${ }^{3}$ Health and Food-Processing Industry Laboratory, Faculty of Sciences and Technics, Hassan 1st University, Settat, Morocco \\ ${ }^{4}$ High Institut of Health Sciences, Hassan 1st University, Settat, Morocco \\ Email: *h_homaid@yahoo.fr
}

How to cite this paper: Houmaid, $\mathrm{H}$., El Bekkay, C., Nassereddine, S., Talbi, H., Amehdare, L. and Hilali, A. (2018) Chromosomal Abnormalities in 238 Couples with Recurrent Miscarriages in Morocco. Open Journal of Genetics, 8, 15-22. https://doi.org/10.4236/ojgen.2018.82002

Received: February 25, 2018

Accepted: June 2, 2018

Published: June 5, 2018

Copyright $\odot 2018$ by authors and Scientific Research Publishing Inc. This work is licensed under the Creative Commons Attribution International License (CC BY 4.0).

http://creativecommons.org/licenses/by/4.0/

\begin{abstract}
Purpose: A proportion of cases with repeated abortion are caused by chromosomal abnormality in one of the parents. The purpose of this study was to assess the frequency and nature of chromosomal aberrations that contribute to the occurrence of recurrent miscarriages. Several studies have been done to determine the role of chromosomal abnormalities in couples with recurrent spontaneous abortion in various countries. None of these studies was done in Morocco. Material and Methods: Cytogenetic study was done for $238 \mathrm{Mo}-$ roccan couples who presented with repeated abortion at the Institut Pasteur, Casablanca, Morocco. Results: We found that the frequency of chromosomal abnormalities was not significantly different from that reported worldwide. Chromosomal abnormalities were detected in 13 (6.1\%) of 238 couples. twelve of chromosomal abnormalities were structural and one of them were numerical. Conclusion: This study highlights the importance of constitutional cytogenetic exploration of couples with a history of repeated spontaneous abortion. Cytogenetic findings could provide valuable information for genetic counseling and allow monitoring of future pregnancies by prenatal diagnosis in couples with a history of recurrent miscarriage.
\end{abstract}

\section{Keywords}

Cytogenetics, Recurrent Abortions, Chromosomal Aberrations

\section{Introduction}

Miscarriage, defined as spontaneous pregnancy loss at $<20$ - 28 weeks gestation, 
is a common clinical problem. Early pregnancy loss in the first trimester is the most common complication, approximately $15 \%-20 \%$ of clinically recognizable pregnancies end in spontaneous abortion [1] [2].

Recurrent miscarriage, defined as three or more consecutive miscarriages, affects up to $3 \%$ of couples trying to conceive [3] [4]. Some investigators feel that even two spontaneous abortions constitute recurrent miscarriage and deserve evaluation [5].

In almost $50 \%$ of cases the etiology is unknown. The causes of RM are heterogeneous and include endocrine dysfunction, auto immune disorders, genetic abnormalities, maternal and paternal age, infectious diseases, environmental toxins and congenital or structural uterine anomalies etc. [6].

Repeated pregnancy losses during the first trimester are usually due to fetal genetic defects. Pregnancies lost in late gestations also have a high rate of chromosomal anomalies, about $30 \%$ in the second trimester and 5\% in the third trimester [7].

The incidence of chromosomal abnormalities in those abortions is as high as $50 \%$ [8]. Chromosomal abnormalities, mainly balanced rearrangements, are common in couples with reproductive disorders including recurrent abortions [9]. In couples with two or more miscarriages the incidence of these abnormalities varies between $3 \%$ and 6\% [10] [11]; when one parent carries a Chromosome rearrangement the chance of miscarriage is usually $25 \%$ - 50\% [12]. This results from the production of gametes and embryos with unbalanced chromosome sets [13] [14].

The clinical consequences of such abnormal gametes include sterility, repeated abortions, and giving birth to malformed children [15] [16].

Several studies have been done in various countries to determine the contribution of chromosome abnormalities in parents with fetal wastage [17].

Cytogenetic studies have been reported to determine the contribution of chromosomal abnormalities in parents with reproductive failure from various other countries.

To our knowledge, no such studies have been done with sample size of 476 cases in Morocco.

The aim of this study was to assess the frequency and nature of chromosomal aberrations that contribute to the occurrence of repeated abortions in Morocco.

\section{Materials and Methods}

A retrospective study was done in couples with RM from the period between January 2010 to May 2015. This study included 238 (476 cases both partner) Moroccan couples with repeated abortions who were referred for cytogenetic studies at Institut Pasteur, Casablanca, Morocco. All cases were ascertained to have had two or more spontaneous abortions. The obstetric history of couples was either recorded on the request form or retrieved from the files of patients. 
All of them had diagnosis more than one spontaneous abortion as we mentioned before. Standard method of 72 hours cultivation of peripheral blood lymphocytes has been applied. Cytogenetic analysis has been performed according to instructions and rules given by International System of Human Chromosomal Nomenclature (ISCN). At least 20 GTG (Gbanding using Trypsin and Giemsa) mitotic cells have been analyzed, if there was doubt of mosaic karyotype, 50 up to 100 cells have been analyzed. C-band has been applied for confirmation of chromosomal heteromorphy.

\section{Result}

A total of 238 couples (476 subjects) with history of recurrent abortion were examined. Their ages ranged from 19 to 60 years, with a mean of 34.22 years. The age range of women was 19 to 46 years, with a mean of 30.14 years and the age range of men was 19 - 60 years, with mean of 38.31 years.

The number of previous abortion varied from 2 to 12 abortions/couple with a mean of 3.69 .

In this study, the 238 couples (476 individuals) studied were classified according to the number of previous miscarriages. In group 1, couples had two miscarriages, in group 2, they had three, in group 3 they had four and more miscarriages. The highest number of patients was seen in group $3(42.85 \%)$ (Table 1).

Among these 238 couples, 13 (5.46\%) were found to be carriers of different chromosomal abnormalities, nine females $(69.23 \%)$ and 4 males $(30.77 \%)$ (Table 2). Twelve of chromosomal abnormalities were structural and one of them were numerical. These abnormalities included eight balanced reciprocal translocations, one Robertsonian translocation, and four pericentric inversion of chromosome 9 (inv [9] [p11q13]) (Table 2).

Chromosome abnormalities were found in $(3 / 57)=5.26 \%$ of the couples with

Table 1. Couples grouped according to the number of miscarriages.

\begin{tabular}{cccc}
\hline & Number of abortion & couples & carriers \\
\hline Group 1 & 2 & $57(23.95 \%)$ & $3 / 57(5.26 \%)$ \\
Group 2 & 3 & $79(33.19 \%)$ & $4 / 79(5.06 \%)$ \\
Group 3 & $\geq 4$ & $102(42.85 \%)$ & $6 / 102(5.88 \%)$ \\
\hline
\end{tabular}

Table 2. Sex distribution of abnormal karyotype.

\begin{tabular}{ccccc}
\hline \multirow{2}{*}{ sex } & \multicolumn{3}{c}{ Abnormal karyotype [13] } & \multirow{2}{*}{ Total } \\
\cline { 2 - 4 } & Rcp & Rob & Inv & \\
\hline male & $3 / 8$ & $1 / 1(100 \%)$ & - & $4(30.77)$ \\
female & $5 / 8$ & - & $4 / 4(100 \%)$ & $9(69.23)$ \\
total & 8 & 1 & 4 & 13 \\
\hline
\end{tabular}

Rcp: reciprocal translocation, Rob: Robertsonian translocation, Inv: inversion. 
a history of two abortions, in $(4 / 79)=5.06 \%$ with three abortions, and in $(6 / 102)$ $=5.88 \%$ with four or more abortions (Table 1 ). Among cases with abnormal karyotype, the mean maternal age was 29.8 and the mean number of abortions was 3.61 per couple. In this study, in couples who reported chromosomal abnormalities only one partner in each couple was affected and the affected individuals showed only one anomaly (Table 3 ).

\section{Discussion}

Recurrent spontaneous abortion (RSA), is a multifactorial disorder that challenges both patients and clinicians technically and emotionally [18]. The American Society for Reproductive Medicine (ASRM) recommends that clinical evaluation for RSA may proceed after two first trimester pregnancy losses, which increases the prevalence of this problem to $5 \%$ of all couples attempting to conceive [19].

Since cytogenetic finding is considered as a "gold standard" it may give valuable clues [4] for the medical evaluation of patients presenting with recurrent miscarriages.

Several studies have been carried out to determine the prevalence of chromosomal aberrations among couples with recurrent abortion. Schmidt (1962) was the first to report the results of cytogenetics analysis in patients with a history of two or more spontaneous abortions. This was followed by a series of cytogenetic studies of couples with a history of repeated pregnancy loss [10].

The incidence of chromosomal abnormalities among those cases varied in different studies, from none [20] to as high as $21.4 \%$ [21].

The variations in the size of the sample, the criteria used for ascertainment of

Table 3. Cytogenetic findings, number of miscarriages and maternal/paternal age in recurrent miscarriage cases with abnormal karyotype.

\begin{tabular}{|c|c|c|c|c|}
\hline Type & Karyotype & Number Of Miscarriage & Age & Sex \\
\hline & $46 \mathrm{XX}, \mathrm{t}(5,10)(\mathrm{p} 15 ; \mathrm{q} 26)$ & 7 & 30 & $\mathrm{~F}$ \\
\hline & $46 X Y, t(13,19)(p 33 ; q 11)$ & 3 & 44 & M \\
\hline & $46 X X, t(1,7)(p 16 ; q 19)$ & 5 & 31 & $\mathrm{~F}$ \\
\hline & $46 \mathrm{XY}, \mathrm{t}(8,8)(\mathrm{p} 22 ; \mathrm{q} 23)$ & 5 & 39 & $\mathrm{M}$ \\
\hline \multirow[t]{4}{*}{$\operatorname{Rec} 8$} & $46 \mathrm{XX}, \mathrm{t}(14 ; 15)(\mathrm{p} 11 ; \mathrm{q} 23)$ & 4 & 25 & $\mathrm{~F}$ \\
\hline & $46 \mathrm{XY}, \mathrm{t}(2,8)(\mathrm{p} 22 ; \mathrm{q} 22)$ & 2 & 38 & $\mathrm{M}$ \\
\hline & $46 \mathrm{XX}, \mathrm{t}(2,11)(\mathrm{p} 14 ; \mathrm{q} 13)$ & 4 & 26 & $\mathrm{~F}$ \\
\hline & $46 \mathrm{XX}, \mathrm{t}(6,11)(\mathrm{p} 21 ; \mathrm{q} 21)$ & 2 & 29 & $\mathrm{~F}$ \\
\hline \multirow[t]{2}{*}{ Rob 1} & $45 \mathrm{XY}, \operatorname{rob}(13,14)(\mathrm{p} 10 ; \mathrm{q} 10)$ & 3 & 37 & $\mathrm{M}$ \\
\hline & $46 \mathrm{XX}, \operatorname{inv}(9)(\mathrm{p} 11 ; \mathrm{q} 13)$ & 3 & 35 & $\mathrm{~F}$ \\
\hline \multirow[t]{3}{*}{ Inv 4} & $46 \mathrm{XX}, \operatorname{inv}(9)(\mathrm{p} 11 ; \mathrm{q} 13)$ & 2 & 38 & $\mathrm{~F}$ \\
\hline & 46XX, inv 9) (p11; q13) & 4 & 28 & $\mathrm{~F}$ \\
\hline & $46 X X, \operatorname{inv}(9)(p 11 ; q 13)$ & 3 & 27 & $\mathrm{~F}$ \\
\hline
\end{tabular}


cases, and the technique of cytogenetic study have contributed to these wide differences between various studies [22]. It is also possible that different populations vary in the incidence of carriers of chromosomal aberrations.

In our study, we found that the incidence of chromosomal abnormalities among couples with repeated abortions was $5.46 \%$, which is not significantly different from the global incidence.

We found that nine women and four men had chromosomal abnormalities, which was a ratio of 2.25. A similar male to female ratio has been found in most of the reported studies. This predominance of females appears to be due to the fact that chromosomal abnormalities are compatible with fertility in females may be associated with sterility in males [15] [10].

The mean maternal age of women carrying chromosomal anomalies was 29.8 years. There was no positive correlation of advanced maternal age with the number of abortions observed in these subjects indicating that the chromosomal abnormalities could arise because of some reasons other than advanced maternal age.

As reported in the literature [10], reciprocal translocations are the most frequent balanced chromosomal anomalies that are detected in couples with recurrent miscarriage in our study.

Indeed, in our study, reciprocal translocations were detected in $3.36 \%$ of couples, followed by inversions (1.68\%). Robertsonian translocations were observed only in $0.42 \%$ of couples. The strong prevalence of reciprocal translocations compared with Robertsonian translocations would be a result of the difference in the segregation modes of these anomalies.

In the present study, there was a frequent occurrence of inversion 9. Pericentric inversion of chromosome 9 (inv [9] [p11q13]) is a frequently seen chromosomal alteration in humans due to its structural organization, making it more prone to breakage. The incidence estimated is $1 \%-3 \%$ of the general population with the lowest among Asians around 0.25\% [23]. Various reports on its association with infertility, recurrent miscarriages, hydatidiform moles, azoospermia, congenital anomalies, growth retardation, and rarely abnormal phenotype have been published [24]. The largest study on inv [9] and have found a higher frequency among females than in males, especially among those who suffer from infertility [25].

This indicates the possibility of inversion having a role in the aetiology of recurrent miscarriage, which may be confirmed by molecular studies. An increased tendency to early miscarriages in familial pericentric inversions has been well documented [26].

Table 2 shows that the distribution of structural chromosomal rearrangements in our study is similar to that reported worldwide Table 4 [27].

Numerical chromosomal aberrations are less frequently encountered among couples with repeated abortions. Those aberrations are usually in the form of sex chromosomal aneuploidy, and they occur in a low frequency $(<0.15 \%$ of cases $)$ [17]. 
Table 4. Worldwide studies of chromosomal rearrangements observed in couples with recurrent miscarriages.

\begin{tabular}{|c|c|c|c|c|c|c|}
\hline & \multirow{2}{*}{$\begin{array}{l}\text { No. of studied } \\
\text { couples }\end{array}$} & \multicolumn{4}{|c|}{ Structural aberration } & \multirow{2}{*}{ Total (\%) } \\
\hline & & Rob & Rcp & Inv & Others & \\
\hline Belgium (Ghent) & 96 & 2 & 6 & - & & $8(8.3 \%)$ \\
\hline France (Paris) & 315 & 5 & 7 & 4 & & $16(5.1 \%)$ \\
\hline Italy (Padua) & 145 & 4 & 4 & 4 & 2 & $14(9.6 \%)$ \\
\hline Japan & 639 & 9 & 19 & 1 & & $29(4.5 \%)$ \\
\hline Netherland (Leiden) & 67 & 3 & 5 & 1 & & $9(13.4 \%)$ \\
\hline Netherland (Rotterdam) & 148 & 3 & 6 & 3 & 2 & $14(9.6 \%)$ \\
\hline Saudi Arabia (Riyadh) & 193 & 1 & 10 & 2 & & $13(6.7 \%)$ \\
\hline Oman & 380 & 3 & 18 & & 7 & $28(5.5 \%)$ \\
\hline
\end{tabular}

This study has shown that the incidence and distribution of chromosomal abnormalities among Moroccan couples with repeated fetal loss is comparable to that reported worldwide.

This should assist physicians in Morocco by increasing their awareness of the frequency of cytogenetic abnormalities in cases with repeated abortions.

\section{Conclusions}

Cytogenetic analysis should be part of the investigation of any couple who have experienced at least two pregnancy losses of unknown origin.

Genetic counseling is essential in the management of couples who have had multiple pregnancy failures. A chromosomal anomaly finding in one of the two parents makes it possible to evaluate the prognosis of future pregnancies because the finding of translocation (reciprocal or Robertsonian) or an inversion in either parent is a strong indication for prenatal diagnosis (amniocentesis or chorionic villus biopsy) in making a precise reproductive decision regarding subsequent pregnancies.

\section{Conflict of Interest}

No conflict of interest was declared by the authors.

\section{References}

[1] French, F.E. and Bierman, J.M. (1967) Probabilities of Fetal Mortality. Public Health Reports, 77, 835-847. https://doi.org/10.2307/4591645

[2] Dejmek, J., Vojtassak, J. and Malova, J. (1992) Cytogenetic Analysis of 1508 Spontaneous Abortions Originating from South Slovakia. European Journal of Obstetrics \& Gynecology and Reproductive Biology, 46, 129-136. https://doi.org/10.1016/0028-2243(92)90257-Y

[3] Services 1982 Reproductive Impairment among Married Couples. In: US Vital and Health Statistics Series 23, 11, National Center of Health Statistics, Hyattsrille, 1982. 
[4] Franssen, M.T., Korevaar, J.C., Leschot, N.J., et al. (2005) Selective Chromosome Analysis in Couples with Two or More Miscarriages. British Medical Journal, 331, 137-141. https://doi.org/10.1136/bmj.38498.669595.8F

[5] Coulam, C.B. (1991) Epidemiology of Recurrent Spontaneous Abortion. American Journal of Reproductive Immunology, 26, 23-27. https://doi.org/10.1111/j.1600-0897.1991.tb00697.x

[6] Stephenson, M.D. (1996) Frequency of Factors Associated with Habitual Abortion in 197 Couples. Fertility and Sterility, 66, 24-27.

[7] Lee, R.M. and Silver, R.M. (2000) Recurrent Pregnancy Loss: Summary and Clinical Recommendations. Seminars in Reproductive Medicine, 18, 433-440. https://doi.org/10.1055/s-2000-13733

[8] Boue, A., Boue, J. and Gropp, A. (1985) Cytogenetics in Pregnancy Wastage. In: Harris, H. and Hirschhorn, K., Eds., Advances in Human Genetics, Vol. 14, Plenum Press, New York, 1-57.

[9] Fryns, J.P. and Van Buggenhout, G. (1998) Structural Chromosome Rearrangements in Couples with Recurrent Fetal Wastage. European Journal of Obstetrics \& Gynecology and Reproductive Biology, 81, 171-176. https://doi.org/10.1016/S0301-2115(98)00185-7

[10] Brackeeleer, M.D. and Dao, T.N. (1990) Cytogenetic Studies in Couples Experiencing Repeated Pregnancy Losses. Human Reproduction, 5, 518-528. https://doi.org/10.1093/oxfordjournals.humrep.a137135

[11] Clifford, K., Flanagan, A.M. and Regan, L. (1994) An Informative Protocol for the Investigation of Recurrent Miscarriage; Preliminary Experience of 500 Consecutive Cases. Human Reproduction, 9, 1328-1332. https://doi.org/10.1093/oxfordjournals.humrep.a138703

[12] Gardner, R.J.M. and Sutherland, G.R. (1996) Chromosome Abnormalities and Genetic Counselling. 2nd Edition, Oxford University Press, New York.

[13] Lindenbaum, R.H. and Bobrow, M. (1975) Reciprocal Translocations in Man: 3:1 Meiotic Disjunction Resulting in 47-45 Chromosome Offspring. Journal of Medical Genetics, 12, 29-43. https://doi.org/10.1136/jmg.12.1.29

[14] Stene, J. and Stengel-Rutkowski, S. (1982) Genetic Risks for Familial Reciprocal Translocations with Special Emphasis on Those Leading to 9p, 10p, 12p, trisomies. Annals of Human Genetics, 46, 41-47. https://doi.org/10.1111/j.1469-1809.1982.tb00694.x

[15] Chandley, A.C., Edmond, P., Christie, S., Gowans, L., Fletcher, J., Frackievicz, A., et al. (1975) Cytogenetics and Infertility in Man. I: Karyotype and Seminal Analysis: Results of a Five-Year Survey of Men Attending a Subfertility Clinic. Annals of Human Genetics, 39, 231-254. https://doi.org/10.1111/j.1469-1809.1975.tb00126.x

[16] Neri, G., Serra, A., Campana, M. and Tedeschi, B. (1983) Reproductive Risks for Translocations: Cytogenetic Study and Analysis of Pregnancy Outcome in 58 Families. American Journal of Medical Genetics, 16, 535-561. https://doi.org/10.1002/ajmg.1320160412

[17] Campana, M., Serra, A. and Neri, G. (1986) Role of Chromosome Aberrations in Recurrent Abortion: A Study of 269 Balanced Translocations. American Journal of Medical Genetics, 24, 341-365. https://doi.org/10.1002/ajmg.1320240214

[18] Rai, R. and Regan, L. (2006) Recurrent Miscarriage. The Lancet, 368, 601-611. https://doi.org/10.1016/S0140-6736(06)69204-0

[19] Practice Committee of the American Society for Reproductive Medicine (2012) 
Evaluation and Treatment of Recurrent Pregnancy Loss: A Committee Opinion. Fertility and Sterility, 98, 1103-1111. https://doi.org/10.1016/j.fertnstert.2012.06.048

[20] Rowley, P.T., Marshall, R. and Ellis, J.R.A. (1963) Genetic and Cytological Study of Repeated Spontaneous Abortion. Annals of Human Genetics, 27, 78-100. https://doi.org/10.1111/j.1469-1809.1963.tb00784.x

[21] Khudr, G. (1974) Cytogenetics of Habitual Abortion: A Review. Obstetrical \& Gynecological Survey, 29, 299-310. https://doi.org/10.1097/00006254-197405000-00001

[22] Tharapel, A.T., Tharapel, S.A. and Bannerman, R.M. (1985) Recurrent Pregnancy Losses and Parental Chromosome Abnormalities: A Review. British Journal of $\mathrm{Ob}$ stetrics and Gynaecology, 92, 899-914. https://doi.org/10.1111/j.1471-0528.1985.tb03069.x

[23] Abdalla, E.M. and EL-Kharadly, R.N. (2012) Pericentric Inversion of Chromosome 9 in a Consanguineous Couple with Molar Pregnancies and Spontaneous Abortions. Laboratory Medicine, 43, 212-216. https://doi.org/10.1309/LMV84B9GVVYOGZKK

[24] Yamada, K. (1992) Population Studies of Inv(9) Chromosomes in 4,300 Japanese: Incidence, Sex Difference and Clinical Significance. The Japanese Journal of Human Genetics, 37, 293-301. https://doi.org/10.1007/BF01883320

[25] Šípek, A., Panczak, A., Mihalová, R., Hrcková, L., Suttrová, E., Sobotka, V., et al. (2015) Pericentric Inversion of Human Chromosome 9 Epidemiology Study in Czech Males and Females. Folia Biologica, 61, 140-146.

[26] Goud, T.M., Mohammed Al Harassi, S., Khalfan Al Salmani, K., Mohammed Al Busaidy, S. and Rajab, A. (2009) Cytogenetic Studies in Couples with Recurrent Miscarriage in the Sultanate of Oman. Reproductive BioMedicine Online, 18, 424-429. https://doi.org/10.1016/S1472-6483(10)60104-6

[27] Gaboon, N.E., Mohamed, A.R., Elsayed, S.M., Zaki, O.K. and Elsayed, M.A. (2015) Structural Chromosomal Abnormalities in Couples with Recurrent Abortion in Egypt. Turkish Journal of Medical Sciences, 45, 208-213. https://doi.org/10.3906/sag-1310-5 